\title{
It only takes one to do many jobs: Amphotericin B as antifungal and immunomodulatory drug
}

\author{
Ana C. Mesa-Arango ${ }^{1,2}$, Liliana Scorzoni ${ }^{1,3}$ and Oscar Zaragoza ${ }^{1 *}$ \\ ${ }^{1}$ Mycology Reference Laboratory, National Centre for Microbiology, Instituto de Salud Carlos III, Majadahonda, Madrid, Spain \\ ${ }^{2}$ Group of Investigative Dermatology, University of Antioquia, Medellín, Colombia \\ ${ }^{3}$ Faculdade de Ciências Farmacêuticas de Araraquara-SP, Laboratório de Micologia Clínica, Universidade Estadual Paulista - UNESP, \\ Araraquara, Sao Paulo, Brazil
}

\section{Edited by:}

Carlos P. Taborda, University of São

Paulo, Brazil

\section{Reviewed by:}

Marcio Rodrigues, Oswaldo Cruz Foundation, Brazil

Guilherme L. Sassaki, Universidade Federal do Paraná, Brazil

Gil Benard, University of São Paulo, Brazil

\section{*Correspondence:}

Oscar Zaragoza, Mycology

Reference Laboratory, National

Centre for Microbiology, Instituto

de Salud Carlos III, Carretera

Majadahonda-Pozuelo, Km2,

Majadahonda, 28220 Madrid, Spain.

e-mail:ozaragoza@isciii.es

\begin{abstract}
"Amphotericin B acts through pore formation at the cell membrane after binding to ergosterol" is an accepted dogma about the action mechanism of this antifungal, and this sentence is widely found in the literature. But after 60 years of investigation, the action mechanism of Amphotericin B is not fully elucidated. Amphotericin B is a polyene substance that is one of the most effective drugs for the treatment of fungal and parasite infections. As stated above, the first mechanism of action described was pore formation after binding to the ergosterol present in the membrane. But it has also been demonstrated that AmB induces oxidative damage in the cells. Moreover, amphotericin B modulates the immune system, and this activity has been related to the protective effect of the molecule, but also to its toxicity in the host. This review tries to provide a general overview of the main aspects of this molecule, and highlight the multiple effects that this molecule has on both the fungal and host cells.
\end{abstract}

Keywords: amphotericin B, pore, oxidative damage, immunomodulation, fungal infection

\section{INTRODUCTION}

The control of invasive fungal infections is based on the use of antifungal drugs, being polyenes, azoles, and echinocandins the main families used in clinical practice. Among these, polyenes are the drugs that have been in use for a longer time, since they were first described in the middle of the twentieth century (Oura et al., 1955). The main polyene used as antifungal drug is Amphotericin B (AmB), which is an amphipatic macrolide. This molecule was discovered in 1950s after a broad screening of Streptomycete cultures that contained antifungal activity. The AmB-producing organism was isolated from a soil sample taken from the Orinoco River region (Venezuela) and was identified as Streptomyces nodosus (Trejo and Bennett, 1963). An intravenous presentation was introduced in the market in 1958 as a sodium deoxycholate solution (D-AmB) (Fungizone-Squibb), which forms a micellar suspension when reconstituted in glucose solution.

$\mathrm{AmB}$ has been used for the treatment of fungal infections and, despite the toxicity and the development of other antifungals, such as azoles and echinocandins, this drug remains as the first line treatment for severe and life threatening systemic infections such as cryptococcal meningitis and invasive zygomycosis (Saag et al., 2000; Waness et al., 2009). AmB is also effective for other mycoses such as aspergillosis, candidiasis, histoplasmosis, blastomycosis, coccidioidomycosis, sporotrichosis, fusariosis, and phaeohyphomycosis in the cases of lack of response to azoles or echinocandins. (Ellis, 2002; Davis and Porter, 2005; Metcalf and Dockrell, 2007; Chandrasekar, 2008; Gomez-Lopez et al., 2008; Muhammed et al., 2011). Additionally, AmB has activity against parasites as Trypanosoma cruzi, Schistosoma mansoni, Echinococcus multilocularis, and Leishmania spp, being the second drug of choice for the treatment for visceral leishmaniasis when antimonials fail or cannot be used (Yardley and Croft, 1999; Reuter et al., 2003; Mone et al., 2010; Paila et al., 2010). Also an amphotericin-derived drug, MS8209, has effect against HIV-1 infection avoiding virus entry to the cell (Pleskoff et al., 1995).

The $\mathrm{D}-\mathrm{AmB}$ formulation has been considered the gold standard for many years and it has broad-spectrum activity. Unfortunately, this formulation is highly nephrotoxic and shows side effects as fevers, malaise, weight loss, headache, hypotension, abdominal pain, nausea, vomiting, diarrhea, normochromic normocytic anemia, and myalgia (Sabra and Branch, 1990; Meunier et al., 1991; Ringden et al., 1991; Gulati et al., 1998; LaniadoLaborin and Cabrales-Vargas, 2009). For this reason, new formulations have been introduced in the last years (Lopez-Berestein et al., 1985; Bohme and Hoelzer, 1996; Gulati et al., 1998; Rust and Jameson, 1998; Walsh et al., 1998; Dupont, 2002). The new presentations have reduced toxicity because they are lipidcarried presentations. These last formulations include a colloidal dispersion with cholesterol sulphate (CD-AmB, Amphotec), a lipidic complex with two phospholipids (LC-AmB, Abelcet) and liposomal AmB (L-AmB, Ambisome), which is integrated into true unilamellar liposomes (Veerareddy and Vobalaboina, 2004; Torrado et al., 2008). These different formulations differ in their price and in the associated toxicity. Lipid-based formulations, and in particular, L-AmB, have reduced nephrotoxicity and have superior efficacy than conventional AmB (Gulati et al., 1998; Saliba and Dupont, 2008). 


\section{MECHANISM OF ACTION OF AMPHOTERICIN B}

The mechanism of action of AmB still is not completely elucidated. AmB has effects on the fungal cell at two different levels: Binding to the ergosterol at the membrane, inducing pore formation and ergosterol sequestration, and induction of oxidative damage. In the following sections we will summarize how AmB exerts these two effects on the fungal cells, which are also summarized in Figure 1.

\section{EFFECTS ON THE FUNGAL MEMBRANE: PORE FORMATION AND ERGOSTEROL SEOUESTRATION}

Early studies suggested that $A m B$ inserts into the fungal lipid bilayer through the hydrophobic domains that bind to ergosterol. As a consequence, multimeric pores are formed, with the lipophilic polyene chains of the antifungal in contact with membrane lipids (Finkelstein and Holz, 1973; Brajtburg et al., 1990). $\mathrm{AmB}$ pores increase the permeability of the fungal membrane to small cations as $\mathrm{K}^{+}, \mathrm{Ca}^{2+}$, and $\mathrm{Mg}^{2+}$ promoting the rapid depletion of intracellular ions and fungal cell death (Kinsky, 1970).
AmB can also bind to other sterols, such as cholesterol, but with a lower affinity (Hsuchen and Feingold, 1973).

Recently, it was proposed that $\mathrm{AmB}$ can exert its action through two complementary mechanisms depending on the interaction of $\mathrm{AmB}$ and sterols: membrane permeabilization and sterol sequestration (Palacios et al., 2011). In this sense, it has been proposed that cholesterol sequestration in the host membrane avoids macrophage-parasite interaction in Leishmania infection as a novel mechanism for AmB in visceral leishmaniasis (Chattopadhyay and Jafurulla, 2011).

Analytical studies have demonstrated that AmB forms two different types of pores, which differ in their substrate specificities and that are formed at different moments. Moreover, they participate differentially in the killing effect of the molecule [see seminal review in Cohen (2010) and Hartsel et al. (1994); Romero et al. (2009)]. After addition of AmB to the cells, the first type of pores that are formed are non-aqueous, which are permeable to monovalent cations and have lower permeability to monovalent anions (Ramos et al., 1996; Romero et al., 2009). Afterwards,

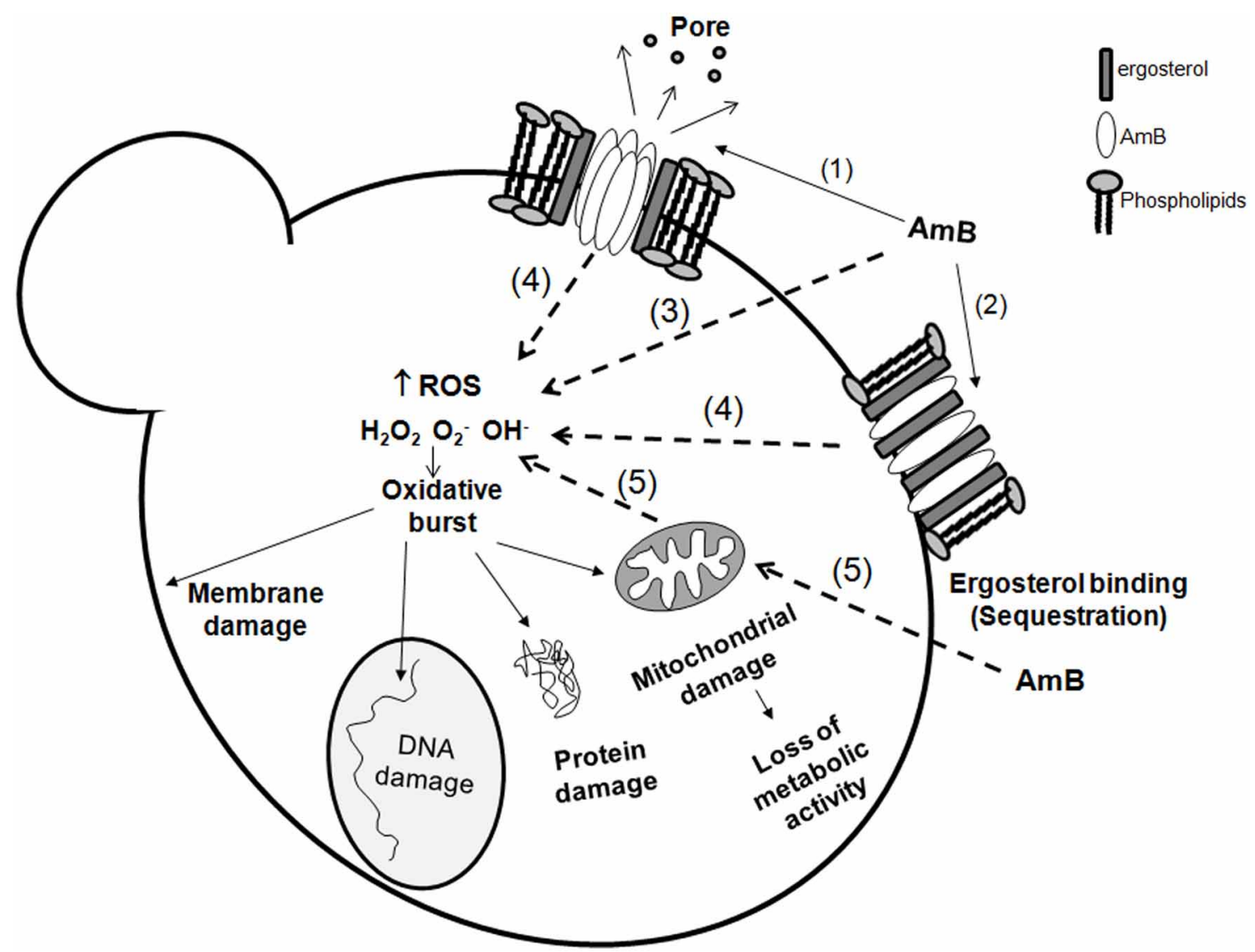

FIGURE 1 | Amphotericin B action mechanisms on fungal cells. Amphotericin B exerts its action at different levels on the cell: membrane effects and intracellular effects. At the membrane, it can bind to ergosterol (1) and form pores, or merely induce ergosterol sequestration (2) resulting in membrane stability disruption. In the cell, AmB also induces an oxidative burst. The mechanism of this induction remains unknown, but there are several possibilities: AmB can act directly as a prooxidant (3) and induce accumulation of reactive oxygen species (ROS). However, it is also possible that this intracellular effect requires previous binding to ergosterol (4). Since ROS are natural products of the respiratory chain, it cannot be discarded that AmB influences the mitochondrial activity (5), and contribute in this way to the oxidative burst. The accumulation of free radicals has multiple deleterious effects on the essential components of the cell (membrane, proteins, DNA and mitochondria) resulting in cell death. 
aqueous-pores are formed, which are permeable to monovalent cations and anions and large electrolytes, such as glucose (Cohen and Gamargo, 1987; Ramos et al., 1989; Cohen et al., 1990; Cohen, 1992). The formation of pores is a very rapid process, and occurs in milliseconds. Furthermore, although AmB has affinities for both ergosterol and cholesterol (Hsuchen and Feingold, 1973), pore formation is delayed in liposomes formed with cholesterol (Mouri et al., 2008). The ergosterol and cholesterol content also determines the concentration at which $\mathrm{AmB}$ forms aqueous or non-aqueous pores, indicating that membrane composition has a profound effect on the AmB action (Mouri et al., 2008).

Ergosterol is required for multiple processes, such as endocytosis, vacuole fusion, and stabilization of proteins at the cell membrane (Heese-Peck et al., 2002; Zhang et al., 2010). So binding of AmB to these molecules could account for the toxic effect of the antifungal by a mechanism that involves ergosterol sequestration. This idea is supported by a recent work (Gray et al., 2012) that demonstrated that channel formation by AmB is a secondary mechanism that enhances the activity of the drug, but is not required to induce killing in the fungal cells. Using different forms of $\mathrm{AmB}$ that had been chemically modified, it was found that modifications that affect pore formation do not affect its antifungal activity. In this sense, it has been shown that other polyenes, such as natamycin, have antifungal effects that are not related to pore formation (Te Welscher et al., 2010).

\section{INDUCTION OF OXIDATIVE DAMAGE}

Although it is well established that $\mathrm{AmB}$ binds to sterols and forms pores, there are numerous articles that indicate that increased permeability might not be the only mechanism responsible for the killing effect of the molecule. Early studies found that there was not correlation between the lethal effect of different polyenes on C. albicans and the degree of potassium release by the cells, suggesting that pore formation does not correlate with killing of the cells (Chen et al., 1978; Sokol-Anderson et al., 1986). This finding indicates that the formation of non-aqueous (cationselective) pores is not enough to induce killing of the cells, and suggests that AmB elicits other killing mechanism. In this sense, it has been observed that the biological effect of $A m B$ is very complex and depends on a variety of factors, such as the growth phase of fungi (Gale, 1974; Gale et al., 1975; Mowat et al., 2008) and the presence of oxygen (Gale et al., 1977; Sokol-Anderson et al., 1986). These data suggest that AmB action depends on metabolic factors, and indicate that the action mechanism is more complex that binding to ergosterol and pore formation. In fact, some studies argue against the idea that pore formation is the main killing mechanism. Chemical modifications of the AmB molecule that interfere with its ability to form pores do not affect its fungicidal activity (Palacios et al., 2007), which provides strong evidence that pore formation is not essential for the function of the molecule.

In agreement with the idea that $\mathrm{AmB}$ has other toxic mechanism than pore formation at the membrane, it has been shown that this antifungal induces oxidative stress in the cells (Sokol-Anderson et al., 1986; Haido and Barreto-Bergter, 1989; Sangalli-Leite et al., 2011). An early study demonstrated that addition of free radicals scavengers, such as catalase and/or superoxide dismutase, protects C. albicans protoplasts from the lytic effect of AmB (Sokol-Anderson et al., 1986). Genome-wide expression analysis confirmed that AmB, not only has an effect on the expression of genes involved in ergosterol synthesis pathway, but also induces the expression of stress genes (Liu et al., 2005), providing another evidence that $\mathrm{AmB}$ has pleiotropic effects in the fungal cells.

The induction of oxidative damage in the cells has been frequently reported in the literature using independent approaches. The direct production of free radicals by $\mathrm{AmB}$ has been measured using probes that emit fluorescence after being attacked by the free radicals, such as dihydrofluorescein diacetate or dihydrorhodamine 123 (Phillips et al., 2003; Sangalli-Leite et al., 2011). Lipid peroxidation, protein carbonylation, and apoptotic-like phenotypes (such as DNA fragmentation and anexin V staining) have been also used as indicators of oxidative stress generated by AmB in fungal cells (Phillips et al., 2003; Mousavi and Robson, 2004; Blum et al., 2008; Al-Dhaheri and Douglas, 2010; Sharma et al., 2010; Sangalli-Leite et al., 2011).

The role of oxidative damage in the antifungal effect of $A m B$ is still unknown, but different studies suggest that this mechanism participates in this effect. A recent study demonstrates that killing of $C$. neoformans cells, measured by propidium iodide uptake, occurs after the induction of an oxidative burst. The mechanism by which AmB induces oxidative burst in the cells remains unknown. Several studies demonstrate that AmB can autooxidize, which suggests a mechanism by which $\mathrm{AmB}$ induces oxidative stress in the cells (Lamy-Freund et al., 1985; Sokol-Anderson et al., 1986). On the other hand, it has been demonstrated that $\mathrm{AmB}$ can also act as an antioxidant similar to carotenoid and retinoids (Osaka et al., 1997).

$\mathrm{AmB}$ induces oxidative damage in organisms others than fungi (Haido and Barreto-Bergter, 1989). Moreover, this feature of the antifungal has been related to the reduction in virulence observed in some parasite infection models. For example, AmB does not have a direct effect on development of the miracidia (larval stages) and sporocyst of the parasite Schistosoma mansoni, but it decreases its infectivity through a process linked to the oxidative damage induced by the antifungal that impaired the response of the parasite during infection (Mone et al., 2010).

\section{MECHANISMS OF RESISTANCE TO AmB}

Acquired resistance to $A m B$ is very low despite its widespread use. Secondary resistance has been described in C. tropicalis, C. parapsilosis, C. lusitanie, and C. haemulonii (Powderly et al., 1988; Ellis, 2002). In contrast, in the last years, there has been an increase in the incidence of infections caused by fungi intrinsically resistant to AmB, such as A. terreus, Fusarium spp, and Scedosporium prolificans (Cuenca-Estrella et al., 1999; Sutton et al., 1999; Khan et al., 2007; Rogasi et al., 2007).

Resistance to this antifungal is achieved in different ways. Decrease in ergosterol content results in resistance to this compound (Kim and Kwon-Chung, 1974; Kim et al., 1974; Woods et al., 1974; Safe et al., 1977; Drutz and Lehrer, 1978; Merz and Sandford, 1979; Kreiner et al., 1993; Kelly et al., 1994; Currie et al., 1995; Ghannoum and Rice, 1999; Walsh et al., 2003; Vandeputte et al., 2007). Most of these studies showed alterations in the ergosterol synthesis pathway and accumulation of sterol intermediates. 
Moreover, in biofilms (which are microbial populations that grow attached to a surface and have reduced susceptibility to antimicrobials), resistance to $\mathrm{AmB}$ has been associated not only to a decrease in the ergosterol content, but also to changes in the cell wall (Khot et al., 2006). Since azoles inhibit ergosterol synthesis, cross resistance between azole and $\mathrm{AmB}$ has been described in the literature (Sud and Feingold, 1983; Kelly et al., 1996, 1997; Nolte et al., 1997; Sanglard et al., 2003).

However, other studies did not find a correlation between ergosterol content and susceptibility to AmB (Joseph-Horne et al., 1996a,b; Dannaoui et al., 2000). In agreement, it has been shown that pre-exposure of $C$. albicans cells to fluconazole can protect the yeasts from AmB treatment, and this effect is still present when ergosterol is added to the medium, suggesting that this resistance phenotype does not depend on ergosterol (Vazquez et al., 1998). Interestingly, it has been recently shown that subinhibitory concentrations of fluconazole induce a response in yeast that confer resistance to oxidative and nitrosative stress (Arana et al., 2010), which supports the idea that adaptation to oxidative stress can result in AmB tolerance. Resistance to AmB has been also studied using genome-wide expression analysis in C. albicans (Barker et al., 2004). This work demonstrated that resistance to $\mathrm{AmB}$ and fluconazole was associated, not only with an increase in the expression or ERG genes, but also with the induction of stress genes such as catalase, and reduction of mitochondrial enzymes, such as cytochrome c oxidase and acetyl CoA synthetase, suggesting that resistance to $\mathrm{AmB}$ could be associated to a decrease in mitochondrial activity and reactive oxygen intermediates (ROIs) production.

A strong support for the role of oxidative damage in the antifungal activity of the drug is provided by the relationship between resistance to $\mathrm{AmB}$ and to oxidant stress. This was first described in $C$. albicans, where it was observed that resistant strains to $\mathrm{AmB}$ had reduced susceptibility to $\mathrm{H}_{2} \mathrm{O}_{2}$ (Sokol-Anderson et al., 1988). In this work, resistance to $\mathrm{AmB}$ and $\mathrm{H}_{2} \mathrm{O}_{2}$ correlated with increased catalase activity. Another evidence of the importance of the oxidative damage was provided in the filamentous fungi Aspergillus terreus, which is considered intrinsically resistant to AmB. This fungus has similar ergosterol levels than a susceptible species, such as A. fumigatus (Dannaoui et al., 2000; Blum et al., 2008). However, AmB did not induce lipid peroxidation in A. terreus, suggesting that this fungus has an induction in antioxidant mechanisms. In agreement, catalase activity in $A$. terreus was significantly higher in this fungus than in A. fumigatus (Blum et al., 2008).

The respiratory chain in the mitochondria plays a key role in the production of free radicals in the cells because these molecules are subproducts of the respiration. So it is tempting to correlate the effect of AmB with the mitochondrial activity. Little is known about this correlation, but it has been demonstrated that disruption of respiratory function results in increased resistance to $\mathrm{AmB}$ in C. albicans (Geraghty and Kavanagh, 2003). This finding is very relevant, especially because the mitochondria is not only required for the accumulation of free radicals, but also because it is necessary for ergosterol biosynthesis, so changes in mitochondrial activity can influence the antifungal activity of $\mathrm{AmB}$ at multiple levels.

\section{AmB AS A MOLECULE WITH IMMUNOMODULATORY PROPERTIES}

Antifungal drugs are derived from natural compounds with complex structure, and many of them have other effects than growth inhibition or killing of fungi. In this sense, antifungals have inmmunomodulatory properties [see review in Ben-Ami et al. (2008)]. AmB is a good example about this type of drugs. Besides the direct action on the fungal cell, several studies have shown that $\mathrm{AmB}$ has a potent immunomodulatory effect on the host cells. This has been demonstrated in vitro in different cellular lines from human and murine models, such as polymorphonuclear neutrophils (PMNs), macrophages, NK cells, T, B, and tumoral cells, but also in vivo in animal models. The immunomodulatory properties offer an alternative action mechanism for this antifungal by enhancing the immune response of the host. But at the same time, this effect has been related to toxicity associated to this drug. In the following sections, we will briefly review the main immunomodulatory properties of AmB.

\section{IMMUNOMODULATION IN VITRO AND IN VIVO}

Multiple studies performed in vitro and in vivo have demonstrated that $\mathrm{AmB}$ has an effect on the host, not only in the presence of the pathogen, but also when uninfected cell lines or animals are treated with the antifungal. AmB stimulates transcription and production of multiple mediators of the immune system (such as cytokines, chemokines, and prostaglandins) and ICAM-1 in murine and human cells (Borden and Leonhardt, 1976; Sculier and Body, 1991; Cleary et al., 1992; Louie et al., 1994; Saxena et al., 1999; Rogers et al., 2000; Sau et al., 2003; Camacho et al., 2004; Simitsopoulou and Roilides, 2005; Simitsopoulou et al., 2005). Moreover, this antifungal upregulates the expression of genes involved in angiogenesis (Lin et al., 2009). AmB also induces the accumulation of nitric oxide (NO) (Mozaffarian et al., 1997) and ROIs (Wilson et al., 1991). Most of these effects are summarize in Figure 2. In endothelial activated cells, AmB increases iNOS expression mediated by endogenous IL-1 and, in consequence, AmB augments the production of NO, which plays important role in vasodilation and protection against pathogens (Suschek et al., 2002).

The immunomodulatory properties and the proinflammatory effect induced by $\mathrm{AmB}$ have been associated with protective effects during infection. AmB enhances the antifungal activity of PMN and pulmonary alveolar macrophages against conidia and/or hyphal phase of $A$. fumigatus (Roilides et al., 2002). Similar results were published with murine peritoneal macrophages pretreated with IFN- $\gamma$ and different doses of AmB. In this case $\mathrm{AmB}$ induced the production of NO, TNF- $\alpha$, and IL- 1 , that enhanced the anticryptococcal activity of these cells (Tohyama et al., 1996).

Macrophage oxidative burst, leading to $\mathrm{O}_{2}^{-}$release, is activated in vivo after intraperitoneal injections of recombinant IFN- $\gamma$ and TNF- $\alpha$ or AmB (Wolf and Massof, 1990). Moreover, when AmB was combined with IFN- $\gamma$, a synergic effect was observed, suggesting that IFN- $\gamma$ may serve as a useful adjuvant during the treatment of intracellular fungal infections.

AmB also produces oxidative burst in macrophages following stimulation with phorbol myristate acetate. This effect was 


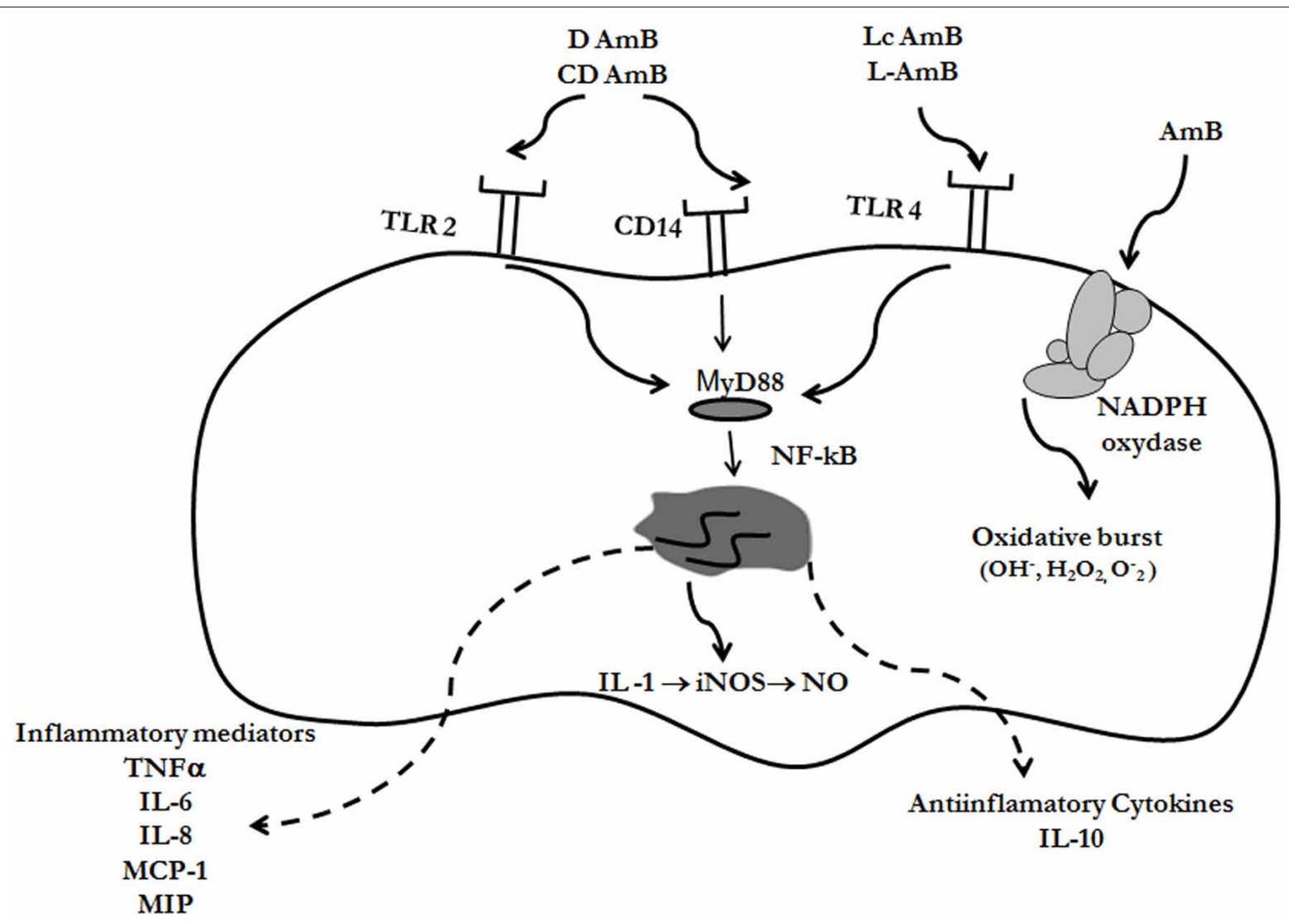

FIGURE 2 | Immunomodulatory effects of AmB. Different formulations of AmB can bind to Toll-like receptors (TLR-2 or TLR-4) or CD14, resulting in immunomodulation of the cell. The signal is transduced through the adaptor protein MyD88, and as a final effect, NF-kB is activated and translocated to the nucleus. In this way, cytokines are expressed, which can be pro- or anti-inflammatory, depending on the AmB formulation, and receptors involved (see text for further details). AmB also induce the accumulation of free radicals (reactive oxygen intermediates, ROIs, and nitric oxide, NO) through induction of $\mathrm{NO}$ synthase and NADPH oxidase related to the binding to the antifungal to the membrane that could in turn induce conformational changes that activate membrane enzymes involved in the induction of oxidative burst, such as NADPH oxidase (Chapman and Hibbs, 1978; Wilson et al., 1991). AmB also has a cooperative effect with IFN- $\gamma$ in enhancing the candidastatic activity of the macrophages through a process that involves the accumulation of ROIs (Coste et al., 2002). However, the same authors also noticed that AmB had a cooperative effect with IL-13, but this effect was independent of ROIs, indicating that AmB can activate macrophages in different ways.

The outcome of systemic and mucosal fungal infections depends on the Th response of the host. Th1 response (which depends on proinflamamatory cytokines TNF- $\alpha$, IFN- $\gamma$, IL- 1 , IL-6) leads to resistance because it primes the immune system with macrophage inflammatory activation and superoxide and NO production. In contrast, a Th2 response (IL-10, IL-4, IL-2, IL-13, and IL-5) is associated with susceptibility to infection and disease enhancement (Puccetti et al., 1995; Romani and Howard, 1995). To evaluate the effect of AmB on the Th cell response, mice with disseminated or gastrointestinal candidiasis were treated with antifungal alone or in combination with an IL-4 antagonist, and the production of IFN- $\gamma$ (Th1) and IL-4 (Th2) was evaluated. AmB induced a protective Th1 response with concomitant IL-4 depletion (Cenci et al., 1997). Similar results were observed in Balb/c mice infected with A. fumigatus spores and treated with AmB (Saxena et al., 1999). In agreement, it was described that AmB induces up-regulation of IL- $1 \beta$ and TNF- $\alpha$ in mouse kidney (Falk et al., 2005). The idea that AmB exerts part of its effect through immunomodulation was supported by the fact the antifungal shows a defect in the protection when mice receive neutralizing TNF- $\alpha$ antibodies (Louie et al., 1995).

Since changes in the immune response could have profound consequences in the host, the immunomodulatory properties of AmB can explain some of the secondary effects of the molecule. For example, the increase in proinflammatory cytokines has been correlated with the toxicity of AmB (Chia and McManus, 1990; Cleary et al., 1992; Arning et al., 1995; Shadkchan et al., 2004). In addition, direct renal toxicity has been described by the induction of apoptosis and alterations in the expression of the constitutive NO synthase (Suschek et al., 2000; Falk et al., 2005; Yano et al., 2009).

$\mathrm{AmB}$ has been occasionally described to have immunosupressor effects. In the human THP-1 monocytic cell line, pretreatment 
with $\mathrm{AmB}$ and challenge with $A$. fumigatus conidia results in reduced expression of TNF- $\alpha$ (Choi et al., 2010). Also Becker et al. observed decrease of IL-6, macrophage inflammatory protein (MIP-2), and monocyte chemoattractant protein (MCP-1) in neutropenic rats with invasive pulmonary aspergillosis treated with AmB (Becker et al., 2003).

\section{MECHANISMS BY WHICH AmB INDUCES IMMUNOMODULATION}

The mechanism by which $\mathrm{AmB}$ produces immunomodulation and induction of ROIs and NO is not fully elucidated. As stated above, AmB binds to the mammalian membrane because it presents affinity to cholesterol, and in this way, it could induce conformational changes that activate the NADPH oxidase enzyme (Chapman and Hibbs, 1978; Wilson et al., 1991) (Figure 2). But the mechanism that better explains the immunomodulatory effects of $\mathrm{AmB}$ is mediated through the Toll-like receptor (TLRs) signaling pathway (Figure 2). TLRs are members of a conserved family of mammalian receptors that recognize microbial products, being TLR2 and TLR4 the best characterized. TLR2 presents affinity for Gram-positive bacteria, peptidoglycan, lipoteichoic acid, and zymosan, whereas TLR4 ligands include LPS from Gram-negative bacteria, Taxol, and Cryptococcus neoformans capsular polysaccharide (Shoham et al., 2001; Janeway et al., 2005). AmB can bind to TLR, resulting in cytokine and chemokine release. Binding to TLR2 has been associated to release of proinflammatory cytokines, while binding to TLR4 produced release of anti-inflammatory (Bellocchio et al., 2005). Binding of $\mathrm{AmB}$ to the TLRs triggers polymerization of receptors which results in recruitment of the adaptor protein, MyD88. This signaling produces the nuclear translocation of NF-kB, which induces the expression of genes involved in macrophage activation. In addition, $\mathrm{AmB}$ also exerts its immunomodulatory effect through CD14 (Trajkovic et al., 2001; Sau et al., 2003), which is a receptor that activates the TLR signaling pathway after binding to LPS.

\section{EFFECT OF THE AmB FORMULATIONS ON THE IMMUNOMODULATORY PROPERTIES}

The immunomodulatory properties of $\mathrm{AmB}$ depend on the clinical presentation used in the treatment. In a study using plasma of patients treated with different presentations, it was found that D-AmB and L-AmB increased TNF- $\alpha$, IL-6, and IL-1-RA, but this effect was not observed when patients were treated with CD-AmB (Arning et al., 1995). In human monocytes $\mathrm{D}-\mathrm{AmB}$ and $\mathrm{CD}-\mathrm{AmB}$ induced up-regulation of inflammatory cytokines such as IL-1, TNF- $\alpha$, monocyte chemotactic protein 1 (MCP-1), and macrophage inflammatory protein 1 (MIP1), while LC-AmB lipid complex and L-AmB down-regulated or had no effect on the gene expression of these proinflammatory cytokines (Simitsopoulou et al., 2005). Moreover, $\mathrm{D}-\mathrm{AmB}$ is more effective than LC-AmB in enhancing PMN oxidative activity and $\mathrm{D}-\mathrm{AmB}$ induced higher expression of CD11b/CD18 integrin (Mac-1) (Sullivan et al., 1992). On the other hand, using antibody arrays, both $\mathrm{D}-\mathrm{AmB}$ and $\mathrm{CD}$ AmB induced proinflammatory cytokines in the THP-1 monocytic cell line (IL-8, TNF- $\gamma$, MCP-1, and RANTES) while
LC-AmB and L-AmB had no effect (Turtinen et al., 2004). This difference between the AmB formulations can be explained by the type of TLR to which the different AmB presentations bind. D-AmB binds to TLR2, which induces a proinflammatory response, in contrast to L-AmB which induces antiinflammatory effect after binding to TLR4 in PMNs (Bellocchio et al., 2005).

\section{CONCLUSIONS AND FUTURE PERSPECTIVES}

$\mathrm{AmB}$ is still an enigmatic molecule, and although it has been vastly used for the treatment of fungal infections during decades, there are still aspects about its action mechanism that remain unknown. Although the first studies demonstrated that this drug binds to sterols and in particular, ergosterol, and forms pores at the membrane, it has been also shown that $\mathrm{AmB}$ induces oxidative damage in the cells. There are contradictory data about the importance of these mechanisms. The fact that resistance to this antifungal correlates with different mechanisms, such as a reduction in ergosterol content or induction of antioxidant enzymes indicates that most probably both are required for the killing effect of the molecule. At the moment, it is not possible to know if these mechanisms are related or are independent, although a tempting hypothesis is that binding to ergosterol is necessary not only for pore formation, but also for the induction of oxidative damage. Further studies are required to clarify the importance of each mechanism. In addition, the induction of different killing mechanisms is in agreement with the fact that $\mathrm{AmB}$ is the antifungal drug with a stronger fungicidal activity. To make the situation more complex, AmB has also strong immunomodulatory properties, and in particular, it induces proinflammatory responses. This effect has been associated with protective effects, but also with the toxicity. The immunomodulatory properties of the antifungal open many questions about how AmB acts during infection, not only on the pathogen, but also on the host. This issue is of particular interest because patients affected by fungal infections are immunocompromised. So it is important to consider that AmB may have different effects on patients with different immunological states and therefore, the antifungal treatment could have unpredicted consequences in the outcome of the disease. Although AmB is one of the most effective treatments for fungal infections and secondary clinical resistance remains low, there is an increase in the incidence of pathogens that have intrinsic resistance to this antifungal, such as Trichosporon spp, A. terreus and Scedosporium prolificans, so more studies are required to understand the basis of intrinsic resistance and to provide an efficient strategy for the management of these infections.

\section{ACKNOWLEDGMENTS}

Ana C. Mesa-Arango is funded by a grant from Fundación Carolina and University of Antioquia, Medellin, Colombia, and Liliana Scorzoni is supported by fellowship from the Agencia Española de Cooperación Internacional para el Desarrollo. Oscar Zaragoza is funded by grant SAF201125140 from the Spanish Ministry for Economics and Competitivity. 


\section{REFERENCES}

Al-Dhaheri, R. S., and Douglas, L. J. (2010). Apoptosis in Candida biofilms exposed to amphotericin B. J. Med. Microbiol. 59, 149-157.

Arana, D. M., Nombela, C., and Pla, J. (2010). Fluconazole at subinhibitory concentrations induces the oxidative- and nitrosativeresponsive genes TRR1, GRE2 and $\mathrm{YHB} 1$, and enhances the resistance of Candida albicans to phagocytes. J. Antimicrob. Chemother. 65, 54-62.

Arning, M., Kliche, K. O., HeerSonderhoff, A. H., and Wehmeier, A. (1995). Infusion-related toxicity of three different amphotericin $\mathrm{B}$ formulations and its relation to cytokine plasma levels. Mycoses 38, 459-465.

Barker, K. S., Crisp, S., Wiederhold, N., Lewis, R. E., Bareither, B., Eckstein, J., Barbuch, R., Bard, M., and Rogers, P. D. (2004). Genomewide expression profiling reveals genes associated with amphotericin $\mathrm{B}$ and fluconazole resistance in experimentally induced antifungal resistant isolates of Candida albicans. J. Antimicrob. Chemother. 54, 376-385.

Becker, M. J., De Marie, S., Fens, M. H., Verbrugh, H. A., and BakkerWoudenberg, I. A. (2003). Effect of amphotericin B treatment on kinetics of cytokines and parameters of fungal load in neutropenic rats with invasive pulmonary aspergillosis. J. Antimicrob. Chemother. 52, 428-434.

Bellocchio, S., Gaziano, R., Bozza, S., Rossi, G., Montagnoli, C., Perruccio, K., Calvitti, M., Pitzurra, L., and Romani, L. (2005). Liposomal amphotericin $B$ activates antifungal resistance with reduced toxicity by diverting Toll-like receptor signalling from TLR-2 to TLR-4. J. Antimicrob. Chemother. 55, 214-222.

Ben-Ami, R., Lewis, R. E., and Kontoyiannis, D. P. (2008). Immunocompromised hosts: immunopharmacology of modern antifungals. Clin. Infect. Dis. 47, 226-235.

Blum, G., Perkhofer, S., Haas, H., Schrettl, M., Wurzner, R., Dierich, M. P., and Lass-Florl, C. (2008). Potential basis for amphotericin $\mathrm{B}$ resistance in Aspergillus terreus. Antimicrob. Agents Chemother. 52, 1553-1555.

Bohme, A., and Hoelzer, D. (1996). Liposomal amphotericin B as early empiric antimycotic therapy of pneumonia in granulocytopenic patients. Mycoses 39, 419-426.
Borden, E. C., and Leonhardt, P. H. (1976). Enhancement of rIn:rCninduced interferon production by amphotericin B. Antimicrob. Agents Chemother. 9, 551-553.

Brajtburg, J., Powderly, W. G., Kobayashi, G. S., and Medoff, G. (1990). Amphotericin B: current understanding of mechanisms of action. Antimicrob. Agents Chemother. 34, 183-188.

Camacho, M., Gerboles, E., Soler, M. and Vila, L. (2004). Modification of prostanoid secretion in endothelial cells by amphotericin B acting synergistically with interleukin-1beta: possible explanation of proinflammatory effects. J. Infect. Dis. 190, 1026-1032.

Cenci, E., Mencacci, A., Del Sero, G., Bistoni, F., and Romani, L. (1997). Induction of protective Th1 responses to Candida albicans by antifungal therapy alone or in combination with an interleukin4 antagonist. J. Infect. Dis. 176, 217-226.

Chandrasekar, P. (2008). Amphotericin B lipid complex: treatment of invasive fungal infections in patients refractory to or intolerant of amphotericin B deoxycholate. Ther. Clin. Risk Manag. 4, 1285-1294.

Chapman, H. A. Jr., and Hibbs, J. B. Jr. (1978). Modulation of macrophage tumoricidal capability by polyene antibiotics: support for membrane lipid as a regulatory determinant of macrophage function. Proc. Natl. Acad. Sci. U.S.A. 75, 4349-4353.

Chattopadhyay, A., and Jafurulla, M. (2011). A novel mechanism for an old drug: amphotericin $\mathrm{B}$ in the treatment of visceral leishmaniasis. Biochem. Biophys. Res. Commun. 416, 7-12.

Chen, W. C., Chou, D. L., and Feingold, D. S. (1978). Dissociation between ion permeability and the lethal action of polyene antibiotics on Candida albicans. Antimicrob. Agents Chemother. 13, 914-917.

Chia, J. K., and McManus, E. J. (1990). In vitro tumor necrosis factor induction assay for analysis of febrile toxicity associated with amphotericin B preparations. Antimicrob. Agents Chemother. 34, 906-908.

Choi, J. H., Kwon, E. Y., Park, C. M., Choi, S. M., Lee, D. G., Yoo, J. H., Shin, W. S., and Stevens, D. A. (2010). Immunomodulatory effects of antifungal agents on the response of human monocytic cells to Aspergillus fumigatus conidia. Med. Mycol. 48, 704-709.

Cleary, J. D., Chapman, S. W., and Nolan, R. L. (1992). Pharmacologic modulation of interleukin-1 expression by amphotericin Bstimulated human mononuclear cells. Antimicrob. Agents Chemother 36, 977-981.

Cohen, B. E. (1992). A sequential mechanism for the formation of aqueous channels by amphotericin $\mathrm{B}$ in liposomes. The effect of sterols and phospholipid composition. Biochim. Biophys. Acta 1108 49-58.

Cohen, B. E. (2010). Amphotericin B membrane action: role for two types of ion channels in eliciting cell survival and lethal effects. J. Membr. Biol. 238, 1-20.

Cohen, B. E., Benaim, G., Ruiz, M. C., and Michelangeli, F. (1990). Increased calcium permeability is not responsible for the rapid lethal effects of amphotericin B on Leishmania sp. FEBS Lett. 259, 286-288.

Cohen, B. E., and Gamargo, M. (1987). Concentration and time dependence of amphotericin Binduced permeability changes across plasma membrane vesicles from Leishmania sp. Drugs. Exp. Clin. Res. 13, 539-546.

Coste, A., Linas, M. D., Cassaing, S. Bernad, J., Chalmeton, S., Seguela, J. P., and Pipy, B. (2002). A subinhibitory concentration of amphotericin B enhances candidastatic activity of interferon-gamma- and interleukin-13-treated murine peritoneal macrophages. J. Antimicrob. Chemother. 49, 731-740.

Cuenca-Estrella, M., Ruiz-Diez, B. Martinez-Suarez, J. V., Monzon, A. and Rodriguez-Tudela, J. L. (1999). Comparative in-vitro activity of voriconazole (UK-109, 496) and six other antifungal agents against clinical isolates of Scedosporium prolificans and Scedosporium apiospermum. J. Antimicrob. Chemother. 43 149-151.

Currie, B., Sanati, H., Ibrahim, A. S. Edwards, J. E. Jr., Casadevall, A., and Ghannoum, M. A. (1995). Sterol compositions and susceptibilities to amphotericin B of environmental Cryptococcus neoformans isolates are changed by murine passage. Antimicrob. Agents Chemother. 39, 1934-1937.

Dannaoui, E., Borel, E., Persat, F. Piens, M. A., and Picot, S. (2000). Amphotericin B resistance of Aspergillus terreus in a murine model of disseminated aspergillosis. J. Med. Microbiol. 49, 601-606.

Davis, L. E., and Porter, B. S. (2005). Central nervous system coccidioides immitis infections. Curr. Treat. Options Neurol. 7, 157-165.
Drutz, D. J., and Lehrer, R. I. (1978). Development of amphotericin Bresistant Candida tropicalis in a patient with defective leukocyte function. Am. J. Med. Sci. 276, 77-92.

Dupont, B. (2002). Overview of the lipid formulations of amphotericin B. J. Antimicrob. Chemother. 49(Suppl. 1), 31-36.

Ellis, D. (2002). Amphotericin B: spectrum and resistance. J. Antimicrob. Chemother. 49(Suppl. 1), 7-10.

Falk, R., Hacham, M., Nyska, A., Foley, J. F., Domb, A. J., and Polacheck, I. (2005). Induction of interleukinlbeta, tumour necrosis factor-alpha and apoptosis in mouse organs by amphotericin B is neutralized by conjugation with arabinogalactan. J. Antimicrob. Chemother. 55, 713-720.

Finkelstein, A., and Holz, R. (1973). Aqueous pores created in thin lipid membranes by the polyene antibiotics nystatin and amphotericin B. Membranes 2, 377-408.

Gale, E. F. (1974). The release of potassium ions from Candida albicans in the presence of polyene antibiotics. J. Gen. Microbiol. 80, 451-465.

Gale, E. F., Johnson, A. M., and Kerridge, D. (1977). The effect of aeration and metabolic inhibitors on resistance to amphotericin in starved cultures of Candida albicans. J. Gen. Microbiol. 99, 77-84.

Gale, E. F., Johnson, A. M., Kerridge, D., and Koh, T. Y. (1975). Factors affecting the changes in amphotericin sensitivity of Candida albicans during growth. J. Gen. Microbiol. 87, 20-36.

Geraghty, P., and Kavanagh, K. (2003). Disruption of mitochondrial function in Candida albicans leads to reduced cellular ergosterol levels and elevated growth in the presence of amphotericin B. Arch. Microbiol. 179, 295-300.

Ghannoum, M. A., and Rice, L. B. (1999). Antifungal agents: mode of action, mechanisms of resistance, and correlation of these mechanisms with bacterial resistance. Clin. Microbiol. Rev. 12, 501-517.

Gomez-Lopez, A., Zaragoza, O., Rodriguez-Tudela, J. L., and Cuenca-Estrella, M. (2008). Pharmacotherapy of yeast infections. Expert Opin. Pharmacother. 9 , 2801-2816.

Gray, K. C., Palacios, D. S., Dailey, I., Endo, M. M., Uno, B. E., Wilcock, B. C., and Burke, M. D. (2012). Amphotericin primarily kills yeast by simply binding ergosterol. Proc. Natl. Acad. Sci. U.S.A 109, 2234-2239. 
Gulati, M., Bajad, S., Singh, S., Ferdous, A. J., and Singh, M. (1998). Development of liposomal amphotericin B formulation. J. Microencapsul. 15, 137-151.

Haido, R. M., and Barreto-Bergter, E. (1989). Amphotericin B-induced damage of Trypanosoma cruzi epimastigotes. Chem. Biol. Interact. 71, 91-103.

Hartsel, S. C., Benz, S. K., Ayenew, W., and Bolard, J. (1994). Na+, K+ and $\mathrm{Cl}$ - selectivity of the permeability pathways induced through sterol-containing membrane vesicles by amphotericin B and other polyene antibiotics. Eur. Biophys. J. 23, 125-132.

Heese-Peck, A., Pichler, H., Zanolari, B., Watanabe, R., Daum, G., and Riezman, H. (2002). Multiple functions of sterols in yeast endocytosis. Mol. Biol. Cell 13, 2664-2680.

Hsuchen, C. C., and Feingold, D. S. (1973). Selective membrane toxicity of the polyene antibiotics: studies on natural membranes. Antimicrob. Agents Chemother. 4, 316-319.

Janeway, C. J., Traverrs, P., Walport, M., and Shlomchik, M. J. (2005). Immunobiology: The Immune System in Health and Disease. New York, NY: Garland Sciences.

Joseph-Horne, T., Loeffler, R. S., Hollomon, D. W., and Kelly, S. L. (1996a). Amphotericin B resistant isolates of Cryptococcus neoformans without alteration in sterol biosynthesis. J. Med. Vet. Mycol. 34, 223-225.

Joseph-Horne, T., Manning, N., Holoman, D., and Kelly, S. (1996b). Nonsterol related resistance in Ustilago maydis to the polyene antifungals, amphotericin B and nystatin. Phytochemistry 42, 637-639.

Kelly, S. L., Lamb, D. C., Kelly, D. E., Loeffler, J., and Einsele, H. (1996). Resistance to fluconazole and amphotericin in Candida albicans from AIDS patients. Lancet 348, 1523-1524.

Kelly, S. L., Lamb, D. C., Kelly, D. E., Manning, N. J., Loeffler, J., Hebart, H., Schumacher, U., and Einsele, H. (1997). Resistance to fluconazole and cross-resistance to amphotericin B in Candida albicans from AIDS patients caused by defective sterol delta5, 6-desaturation. FEBS Lett. 400, 80-82.

Kelly, S. L., Lamb, D. C., Taylor, M., Corran, A. J., Baldwin, B. C., and Powderly, W. G. (1994). Resistance to amphotericin B associated with defective sterol delta $8->7$ isomerase in a Cryptococcus neoformans strain from an AIDS patient. FEMS Microbiol. Lett. 122, 39-42.

Khan, Z. U., Al-Sweih, N. A., Ahmad, S., Al-Kazemi, N., Khan, S., Joseph, L., and Chandy, R. (2007). Outbreak of fungemia among neonates caused by Candida haemulonii resistant to amphotericin B, itraconazole, and fluconazole. J. Clin. Microbiol. 45, 2025-2027.

Khot, P. D., Suci, P. A., Miller, R. L., Nelson, R. D., and Tyler, B. J. (2006). A small subpopulation of blastospores in Candida albicans biofilms exhibit resistance to amphotericin B associated with differential regulation of ergosterol and beta-1, 6-glucan pathway genes. Antimicrob. Agents Chemother. 50, 3708-3716.

Kim, S. J., and Kwon-Chung, K. J. (1974). Polyene-resistant mutants of Aspergillus fennelliae: sterol content and genetics. Antimicrob. Agents Chemother. 6, 102-113.

Kim, S. J., Kwon-Chung, K. J., Milne, G. W., and Prescott, B. (1974). Polyene-resistant mutants of Aspergillus fennelliae: identification of sterols. Antimicrob. Agents Chemother. 6, 405-410.

Kinsky, S. C. (1970). Antibiotic interaction with model membranes. Annu. Rev. Pharmacol. 10, 119-142.

Kreiner, V. G., Vybornykh, S. N., Baranova, N. A., and Egorov, N. S. (1993). The effect of lovastatin on sterol synthesis and yeast resistance to polyene antibiotics. Antibiot. Khimioter. 38, 16-19.

Lamy-Freund, M. T., Ferreira, V. F., and Schreier, S. (1985). Mechanism of inactivation of the polyene antibiotic amphotericin B. Evidence for radical formation in the process of autooxidation. J. Antibiot. (Tokyo) 38, 753-757.

Laniado-Laborin, R., and CabralesVargas, M. N. (2009). Amphotericin B: side effects and toxicity. Rev. Iberoam. Micol. 26, 223-227.

Lin, Z. Y., Chuang, W. L., and Chuang, Y. H. (2009). Amphotericin B upregulates angiogenic genes in hepatocellular carcinoma cell lines. Eur. J. Clin. Invest. 39, 239-245.

Liu, T. T., Lee, R. E., Barker, K. S., Wei, L., Homayouni, R., and Rogers, P. D. (2005). Genome-wide expression profiling of the response to azole, polyene, echinocandin, and pyrimidine antifungal agents in Candida albicans. Antimicrob. Agents Chemother. 49, 2226-2236.

Lopez-Berestein, G., Fainstein, V., Hopfer, R., Mehta, K., Sullivan, M. P., Keating, M., Rosenblum, M. G., Mehta, R., Luna, M., Hersh, E. M., Reuben, J., Juliano, R. L., and Bodey, G. P. (1985). Liposomal amphotericin B for the treatment of systemic fungal infections in patients with cancer: a preliminary study. J. Infect. Dis. 151, 704-710.

Louie, A., Baltch, A. L., Franke, M. A., Smith, R. P., and Gordon, M. A. (1994). Comparative capacity of four antifungal agents to stimulate murine macrophages to produce tumour necrosis factor alpha: an effect that is attenuated by pentoxifylline, liposomal vesicles, and dexamethasone. J. Antimicrob. Chemother. 34, 975-987.

Louie, A., Baltch, A. L., Smith, R. P., Franke, M. A., Ritz, W. J., Singh, J. K., and Gordon, M. A. (1995). Fluconazole and amphotericin B antifungal therapies do not negate the protective effect of endogenous tumor necrosis factor in a murine model of fatal disseminated candidiasis. J. Infect. Dis. 171, 406-415.

Merz, W. G., and Sandford, G. R (1979). Isolation and characterization of a polyene-resistant variant of Candida tropicalis. J. Clin. Microbiol. 9, 677-680.

Metcalf, S. C., and Dockrell, D. H. (2007). Improved outcomes associated with advances in therapy for invasive fungal infections in immunocompromised hosts. J. Infect. 55, 287-299.

Meunier, F., Prentice, H. G., and Ringden, O. (1991). Liposomal amphotericin B (AmBisome): safety data from a phase II/III clinical trial. J. Antimicrob. Chemother. 28(Suppl. B), 83-91.

Mone, Y., Mitta, G., Duval, D., and Gourbal, B. E. (2010). Effect of amphotericin B on the infection success of Schistosoma manson in Biomphalaria glabrata. Exp. Parasitol. 125, 70-75.

Mouri, R., Konoki, K., Matsumori, N., Oishi, T., and Murata, M. (2008). Complex formation of amphotericin B in sterol-containing membranes as evidenced by surface plasmon resonance. Biochemistry 47, 7807-7815.

Mousavi, S. A., and Robson, G. D. (2004). Oxidative and amphotericin B-mediated cell death in the opportunistic pathogen Aspergillus fumigatus is associated with an apoptotic-like phenotype. Microbiology 150, 1937-1945.

Mowat, E., Lang, S., Williams, C., Mcculloch, E., Jones, B., and Ramage, G. (2008). Phasedependent antifungal activity against Aspergillus fumigatus developing multicellular filamentous biofilms. J. Antimicrob. Chemother. $62,1281-1284$
Mozaffarian, N., Berman, J. W., and Casadevall, A. (1997). Enhancement of nitric oxide synthesis by macrophages represents an additional mechanism of action for amphotericin B. Antimicrob. Agents Chemother. 41, 1825-1829.

Muhammed, M., Coleman, J. J., Carneiro, H. A., and Mylonakis, E. (2011). The challenge of managing fusariosis. Virulence 2, 91-96.

Nolte, F. S., Parkinson, T., Falconer, D. J., Dix, S., Williams, J., Gilmore, C., Geller, R., and Wingard, J. R. (1997). Isolation and characterization of fluconazole- and amphotericin B-resistant Candida albicans from blood of two patients with leukemia. Antimicrob. Agents Chemother. 41, 196-199.

Osaka, K., Ritov, V. B., Bernardo, J. F., Branch, R. A., and Kagan, V. E. (1997). Amphotericin B protects cis-parinaric acid against peroxyl radical-induced oxidation: amphotericin B as an antioxidant. Antimicrob. Agents Chemother. 41, 743-747.

Oura, M., Sternberg, T. H., and Wright, E. T. (1955). A new antifungal antibiotic, amphotericin B. Antibiot. Annu. 3, 566-573.

Paila, Y. D., Saha, B., and Chattopadhyay, A. (2010). Amphotericin B inhibits entry of Leishmania donovani into primary macrophages. Biochem. Biophys. Res. Commun. 399, 429-433.

Palacios, D. S., Anderson, T. M., and Burke, M. D. (2007). A post-PKS oxidation of the amphotericin $\mathrm{B}$ skeleton predicted to be critical for channel formation is not required for potent antifungal activity. J. Am. Chem. Soc. 129, 13804-13805.

Palacios, D. S., Dailey, I., Siebert, D. M., Wilcock, B. C., and Burke, M. D. (2011). Synthesis-enabled functional group deletions reveal key underpinnings of amphotericin B ion channel and antifungal activities. Proc. Natl. Acad. Sci. U.S.A. 108, 6733-6738.

Phillips, A. J., Sudbery, I., and Ramsdale, M. (2003). Apoptosis induced by environmental stresses and amphotericin B in Candida albicans. Proc. Natl. Acad. Sci. U.S.A. 100, 14327-14332.

Pleskoff, O., Seman, M., and Alizon, M. (1995). Amphotericin B derivative blocks human immunodeficiency virus type 1 entry after CD4 binding: effect on virus-cell fusion but not on cell-cell fusion. J. Virol. 69, 570-574.

Powderly, W. G., Kobayashi, G. S., Herzig, G. P., and Medoff, G. (1988). Amphotericin B-resistant 
yeast infection in severely immunocompromised patients. Am. J. Med. 84, 826-832.

Puccetti, P., Romani, L., and Bistoni, F. (1995). A TH1-TH2-like switch in candidiasis: new perspectives for therapy. Trends Microbiol. 3, 237-240.

Ramos, H., Attias De Murciano, A., Cohen, B. E., and Bolard, J. (1989). The polyene antibiotic amphotericin B acts as a $\mathrm{Ca} 2+$ ionophore in sterol-containing liposomes. Biochim. Biophys. Acta 982, 303-306.

Ramos, H., Valdivieso, E., Gamargo, M., Dagger, F., and Cohen, B. E. (1996). Amphotericin B kills unicellular leishmanias by forming aqueous pores permeable to small cations and anions. J. Membr. Biol. 152, 65-75.

Reuter, S., Merkle, M., Brehm, K., Kern, P., and Manfras, B. (2003). Effect of amphotericin B on larval growth of Echinococcus multilocularis. Antimicrob. Agents Chemother. 47, 620-625.

Ringden, O., Meunier, F., Tollemar, J., Ricci, P., Tura, S., Kuse, E., Viviani, M. A., Gorin, N. C., Klastersky, J., Fenaux, P., Prentice, H. G., and Ksionski, G. (1991). Efficacy of amphotericin B encapsulated in liposomes (AmBisome) in the treatment of invasive fungal infections in immunocompromised patients. J. Antimicrob. Chemother. 28(Suppl. B), 73-82.

Rogasi, P. G., Zanazzi, M., Nocentini, J., Fantoni, E., Trotta, M., Faggi, E., Fontanelli, A., Bertoni, E., Salvadori, M., and Leoncini, F. (2007). Disseminated Scedosporium apiospermum infection in renal transplant recipient: long-term successful treatment with voriconazole: a case report. Transplant. Proc. 39, 2033-2035.

Rogers, P. D., Stiles, J. K., Chapman, S. W., and Cleary, J. D. (2000). Amphotericin B induces expression of genes encoding chemokines and cell adhesion molecules in the human monocytic cell line THP-1. J. Infect. Dis. 182, 1280-1283.

Roilides, E., Lyman, C. A., Filioti, J., Akpogheneta, O., Sein, T., Lamaignere, C. G., Petraitiene, R., and Walsh, T. J. (2002). Amphotericin B formulations exert additive antifungal activity in combination with pulmonary alveolar macrophages and polymorphonuclear leukocytes against Aspergillus fumigatus. Antimicrob. Agents Chemother. 46, 1974-1976.

Romani, L., and Howard, D. H. (1995). Mechanisms of resistance to fungal infections. Curr. Opin. Immunol. 7, 517-523.

Romero, E. A., Valdivieso, E., and Cohen, B. E. (2009). Formation of two different types of ion channels by amphotericin B in human erythrocyte membranes. J. Membr. Biol. 230, 69-81.

Rust, D. M., and Jameson, G. (1998). The novel lipid delivery system of amphotericin B: drug profile and relevance to clinical practice. Oncol. Nurs. Forum 25, 35-48.

Saag, M. S., Graybill, R. J., Larsen, R. A., Pappas, P. G., Perfect, J. R., Powderly, W. G., Sobel, J. D., and Dismukes, W. E. (2000). Practice guidelines for the management of cryptococcal disease. Infectious diseases society of america. Clin. Infect. Dis. 30, 710-718.

Sabra, R., and Branch, R. A. (1990). Amphotericin B nephrotoxicity. Drug Saf. 5, 94-108.

Safe, L. M., Safe, S. H., Subden, R. E., and Morris, D. C. (1977). Sterol content and polyene antibiotic resistance in isolates of Candida krusei, Candida parakrusei, and Candida tropicalis. Can. J. Microbiol. 23, 398-401.

Saliba, F., and Dupont, B. (2008). Renal impairment and amphotericin B formulations in patients with invasive fungal infections. Med. Mycol. 46, 97-112.

Sangalli-Leite, F., Scorzoni, L., MesaArango, A. C., Casas, C., Herrero, E., Gianinni, M. J., Rodriguez-Tudela, J. L., Cuenca-Estrella, M., and Zaragoza, O. (2011). Amphotericin B mediates killing in Cryptococcus neoformans through the induction of a strong oxidative burst. Microbes Infect. 13, 457-467.

Sanglard, D., Ischer, F., Parkinson, T., Falconer, D., and Bille, J. (2003). Candida albicans mutations in the ergosterol biosynthetic pathway and resistance to several antifungal agents. Antimicrob. Agents Chemother. 47, 2404-2412.

Sau, K., Mambula, S. S., Latz, E., Henneke, P., Golenbock, D. T., and Levitz, S. M. (2003). The antifungal drug amphotericin B promotes inflammatory cytokine release by a Toll-like receptor- and CD14-dependent mechanism. J. Biol. Chem. 278, 37561-37568.

Saxena, S., Bhatnagar, P. K., Ghosh, P. C., and Sarma, P. U. (1999). Effect of amphotericin B lipid formulation on immune response in aspergillosis. Int. J. Pharm. 188, 19-30.

Sculier, J. P., and Body, J. J. (1991). Intravenous administration of amphotericin B entrapped in liposomes: induction of high serum levels of TNF alpha. Ann. Oncol. 2, 141-144.

Shadkchan, Y., Keisari, Y., and Segal, E. (2004). Cytokines in mice treated with amphotericin B-intralipid. Med. Mycol. 42, 123-128.

Sharma, M., Manoharlal, R., Negi, A. S., and Prasad, R. (2010). Synergistic anticandidal activity of pure polyphenol curcumin I in combination with azoles and polyenes generates reactive oxygen species leading to apoptosis. FEMS Yeast Res. 10, 570-578.

Shoham, S., Huang, C., Chen, J. M., Golenbock, D. T., and Levitz, S. M. (2001). Toll-like receptor 4 mediates intracellular signaling without TNF-alpha release in response to Cryptococcus neoformans polysaccharide capsule. J. Immunol. 166, 4620-4626.

Simitsopoulou, M., and Roilides, E. (2005). Evaluation of immunotherapy in invasive candidiasis: antifungal activity and cytokine expression assays. Methods Mol. Med. 118, 161-179.

Simitsopoulou, M., Roilides, E., Dotis, J., Dalakiouridou, M., Dudkova, F., Andreadou, E., and Walsh, T. J. (2005). Differential expression of cytokines and chemokines in human monocytes induced by lipid formulations of amphotericin B. Antimicrob. Agents Chemother. 49, 1397-1403.

Sokol-Anderson, M., Sligh, J. E. Jr., Elberg, S., Brajtburg, J., Kobayashi, G. S., and Medoff, G. (1988). Role of cell defense against oxidative damage in the resistance of Candida albicans to the killing effect of amphotericin B. Antimicrob. Agents Chemother. 32, 702-705.

Sokol-Anderson, M. L., Brajtburg, J., and Medoff, G. (1986). Amphotericin B-induced oxidative damage and killing of Candida albicans. J. Infect. Dis. 154, 76-83.

Sud, I. J., and Feingold, D. S. (1983). Effect of ketoconazole on the fungicidal action of amphotericin B in Candida albicans. Antimicrob. Agents Chemother. 23, 185-187.

Sullivan, G. W., Carper, H. T., and Mandell, G. L. (1992). Lipid complexing decreases amphotericin B inflammatory activation of human neutrophils compared with that of a desoxycholate-suspended preparation of amphotericin B (Fungizone). Antimicrob. Agents Chemother. 36, 39-45.

Suschek, C. V., Bonmann, E., Kapsokefalou, A., Hemmrich, K., Kleinert, H., Forstermann, U., Kroncke, K. D., Mahotka, C. and Kolb-Bachofen, V. (2002).
Revisiting an old antimicrobial drug: amphotericin B induces interleukin-1-converting enzyme as the main factor for inducible nitric-oxide synthase expression in activated endothelia. Mol. Pharmacol. 62, 936-946.

Suschek, C. V., Bonmann, E., Kleinert, H., Wenzel, M., Mahotka, C., Kolb, H., Forstermann, U., Gerharz, C. D., and Kolb-Bachofen, V. (2000). Amphotericin B severely affects expression and activity of the endothelial constitutive nitric oxide synthase involving altered mRNA stability. Br. J. Pharmacol. 131, 473-481.

Sutton, D. A., Sanche, S. E., Revankar, S. G., Fothergill, A. W., and Rinaldi, M. G. (1999). In vitro amphotericin $B$ resistance in clinical isolates of Aspergillus terreus, with a head-tohead comparison to voriconazole. J. Clin. Microbiol. 37, 2343-2345.

Te Welscher, Y. M., Jones, L., Van Leeuwen, M. R., Dijksterhuis, J., De Kruijff, B., Eitzen, G., and Breukink, E. (2010). Natamycin inhibits vacuole fusion at the priming phase via a specific interaction with ergosterol. Antimicrob. Agents Chemother. 54, 2618-2625.

Tohyama, M., Kawakami, K., and Saito, A. (1996). Anticryptococcal effect of amphotericin B is mediated through macrophage production of nitric oxide. Antimicrob. Agents Chemother. 40, 1919-1923.

Torrado, J. J., Espada, R., Ballesteros, M. P., and Torrado-Santiago, S. (2008). Amphotericin B formulations and drug targeting. J. Pharm. Sci. 97, 2405-2425.

Trajkovic, V., Markovic, M., Samardzic, T., Miljkovic, D. J., Popadic, D., and Mostarica Stojkovic, M. (2001). Amphotericin B potentiates the activation of inducible nitric oxide synthase and causes nitric oxide-dependent mitochondrial dysfunction in cytokine-treated rodent astrocytes. Glia 35, 180-188.

Trejo, W. H., and Bennett, R. E. (1963). Streptomyces nodosus sp. n., the amphotericin-producing organism. J. Bacteriol. 85, 436-439.

Turtinen, L. W., Prall, D. N., Bremer, L. A., Nauss, R. E., and Hartsel, S. C. (2004). Antibody array-generated profiles of cytokine release from THP-1 leukemic monocytes exposed to different amphotericin B formulations. Antimicrob. Agents Chemother. 48, 396-403.

Vandeputte, P., Tronchin, G., Berges, T., Hennequin, C., Chabasse, D., and Bouchara, J. P. (2007). Reduced susceptibility to polyenes associated with a missense mutation in 
the ERG6 gene in a clinical isolate of Candida glabrata with pseudohyphal growth. Antimicrob. Agents Chemother. 51, 982-990.

Vazquez, J. A., Arganoza, M. T., Boikov, D., Yoon, S., Sobel, J. D., and Akins, R. A. (1998). Stable phenotypic resistance of Candida species to amphotericin B conferred by preexposure to subinhibitory levels of azoles. J. Clin. Microbiol. 36, 2690-2695.

Veerareddy, P. R., and Vobalaboina, V. (2004). Lipid-based formulations of amphotericin B. Drugs Today (Barc) 40, 133-145.

Walsh, T. J., Hiemenz, J. W., Seibel, N. L., Perfect, J. R., Horwith, G., Lee, L., Silber, J. L., Dinubile, M. J., Reboli, A., Bow, E., Lister, J., and Anaissie, E. J. (1998). Amphotericin B lipid complex for invasive fungal infections: analysis of safety and efficacy in 556 cases. Clin. Infect. Dis. 26, 1383-1396.

Walsh, T. J., Petraitis, V., Petraitiene, R., Field-Ridley, A., Sutton, D., Ghannoum, M., Sein, T., Schaufele, R., Peter, J., Bacher, J., Casler, H., Armstrong, D., Espinel-Ingroff,
A., Rinaldi, M. G., and Lyman, C. A. (2003). Experimental pulmonary aspergillosis due to Aspergillus terreus: pathogenesis and treatment of an emerging fungal pathogen resistant to amphotericin B. J. Infect. Dis. 188, 305-319.

Waness, A., Dawsari, G. A., and Jahdali, H. A. (2009). The rise of an oppurtunistic infection called "Invasive Zygomycosis”. J. Glob. Infect. Dis. 1, 131-138.

Wilson, E., Thorson, L., and Speert, D. P. (1991). Enhancement of macrophage superoxide anion production by amphotericin B. Antimicrob. Agents Chemother. 35, 796-800.

Wolf, J. E., and Massof, S. E. (1990). In vivo activation of macrophage oxidative burst activity by cytokines and amphotericin B. Infect. Immun. 58, 1296-1300.

Woods, R. A., Bard, M., Jackson, I. E., and Drutz, D. J. (1974). Resistance to polyene antibiotics and correlated sterol changes in two isolates of Candida tropicalis from a patient with an amphotericin B-resistant funguria. J. Infect. Dis. 129 , 53-58.

Yano, T., Itoh, Y., Kawamura, E., Maeda, A., Egashira, N., Nishida, M., Kurose, H., and Oishi, R. (2009). Amphotericin B-induced renal tubular cell injury is mediated by $\mathrm{Na}+$ Influx through ionpermeable pores and subsequent activation of mitogen-activated protein kinases and elevation of intracellular $\mathrm{Ca} 2+$ concentration. Antimicrob. Agents Chemother. 53, 1420-1426.

Yardley, V., and Croft, S. L. (1999). In vitro and in vivo activity of amphotericin B-lipid formulations against experimental Trypanosoma cruzi infections. Am. J. Trop. Med. Hyg. 61, 193-197.

Zhang, Y. Q., Gamarra, S., GarciaEffron, G., Park, S., Perlin, D. S., and Rao, R. (2010) Requirement for ergosterol in V-ATPase function underlies antifungal activity of azole drugs. PLoS Pathog. 6:e1000939. doi: 10.1371/journal.ppat.1000939
Conflict of Interest Statement: The authors declare that the research was conducted in the absence of any commercial or financial relationships that could be construed as a potential conflict of interest.

Received: 07 May 2012; paper pending published: 28 May 2012; accepted: 21 July 2012; published online: 08 August 2012.

Citation: Mesa-Arango AC, Scorzoni L and Zaragoza $O$ (2012) It only takes one to do many jobs: Amphotericin B as antifungal and immunomodulatory drug. Front. Microbio. 3:286. doi: 10.3389/ fmicb.2012.00286

This article was submitted to Frontiers in Fungi and Their Interactions, a specialty of Frontiers in Microbiology.

Copyright (C) 2012 Mesa-Arango, Scorzoni and Zaragoza. This is an open-access article distributed under the terms of the Creative Commons Attribution License, which permits use, distribution and reproduction in other forums, provided the original authors and source are credited and subject to any copyright notices concerning any third-party graphics etc. 